\title{
Notch Effect on Multiaxial Low Cycle Fatigue
}

\author{
Masao Sakane ${ }^{1}$, Shengde Zhang ${ }^{2}$ and Kim TaeJoon ${ }^{3}$ \\ ${ }^{1}$ Department of Mechanical Engineering, Faculty of Science and Engineering, \\ Ritsumeikan University, 1-1-1, Nojihigashi, Kusatsu-shi, Shiga 525-8577, Japan \\ Email: sakanem@se.ritsumei.ac.jp \\ ${ }^{2}$ Department of Mechanical Engineering, Faculty of Science and Engineering, \\ Ritsumeikan University, 1-1-1, Nojihigashi, Kusatsu-shi, Shiga 525-8577, Japan \\ Email: zhangsd@se.ritsumei.ac.jp \\ ${ }^{3}$ Department of Mechanical Engineering, Faculty of Science and Engineering, \\ Ritsumeikan University, 1-1-1, Nojihigashi, Kusatsu-shi, Shiga 525-8577, Japan \\ Email: gr016060@ed.ritsumei.ac.jp
}

ABSTRACT. This paper discusses the notch effect on multiaxial low cycle fatigue. Neuber's rule was firstly introduced to estimate the local strain at the notch root in proportional tension and torsion loading. The Neuber's rule was applied to estimating crack initiation and for propagation lives in tension-torsion low cycle fatigue. The rule conservatively estimated the crack initiation life in tension low cycle fatigue and appropriately in torsion low cycle fatigue. A simple method for estimating the local strain at the notch root was proposed in tension and torsion loading. The notch effect in nonproportional low cycle fatigue was discussed in two materials. The local strain at the notch root obtained by finite element analysis underestimated the crack initiation lives for the additional hardening material but that obtained by the Neuber's rule overestimated for the non-additional hardening material.

\section{INTRODUCTION}

Structures and components always have geometrical discontinuities like bolt holes, corners, non-uniform cross section, etc., that are understood as the notch and numerous studies were performed to evaluate local stresses and strains around the notch[1-3]. Elastic stress concentration factors have been widely used to express the local stress and strain at the notch root. Neuber derived the stress concentration factors of many geometrical shapes and loading modes [4].

Fatigue lives are significantly reduced by notches because of higher stresses at the notch part. High cycle fatigue lives of notched components have been well studied in relation with the peak stress and stress gradient at the notch root using the fatigue strength reduction factor and the fatigue notch sensitivity factor. All components except the vicinity at the notched part deform elastically and the elastic theory is basically applicable to the high cycle fatigue strength of notched components.

In low cycle fatigue, on the other hand, most part deforms plastically and elastic theory is no longer applicable to estimating the stress and strain concentration. The Neuber's 
rule [5] has been widely used to estimate the stress and strain concentration at the notch root because of its simplicity but the rule overestimates the strain concentration in uniaxial tension. The reason of the overestimation results from that the rule was derived in pure shear so that the rule does not accurately estimate the stress and strain concentration in tension.

The notch effect on multiaxial low cycle fatigue is especially important to estimate low cycle fatigue lives of notched components subjected to multiaxial loading but a limited number of studies have been reported[2,3]. Especially, notch study in low cycle fatigue under nonproportional loading is little. This paper overviews the notch study in low cycle fatigue in proportional and nonproportional loading. This paper does not intend to make a literature survey of broad notch studies but intend to present the notch studies performed in the author's laboratory. Readers are able to refer the systematic literature survey in the references [1-3].

\section{NOTCH THEORY}

Finite element analysis is applicable to estimating local strains at notch parts (Design by Analysis) but the method has a disadvantage of high cost charged to the price of products. Designers prefer simpler method like the Neuber's rule in practice to suppress the designing cost low (Design by Rule), so that a simple method of estimating local stresses and strains at notched part is needed.

Typical method of estimating the local stress and strain is the Neuber's rule [5] expressed by the following equation.

$$
K_{\sigma} K_{\varepsilon}=K_{t}^{2}
$$

In the equation, $K_{\sigma}$ and $K_{\varepsilon}$ are the inelastic stress and strain concentration factors at the notch root and $K_{t}$ is the elastic stress concentration factor. The rule was derived in pure shear but the rule has been historically applied to the push-pull loading because of its theoretical background and simplicity [6].

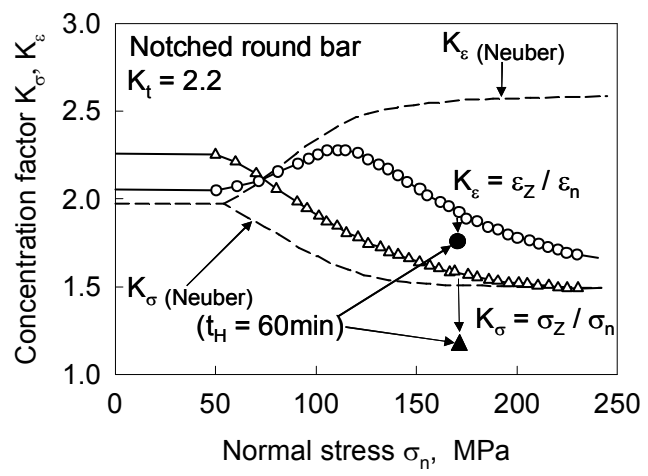

Figure 1. Comparison of the stress and strain concentration factors between Neuber's rule and finite element analysis for a round notched bar with $\mathrm{K}_{\mathrm{t}}=2.2$. 
Figure 1 compares the stress and strain concentration factors obtained by finite element analysis with those calculated in Eq.(1) for a round notched bar with the elastic stress concentration factor of 2.2. The stress and strain concentration factors take constant values in the nominal stress range less than $50 \mathrm{MPa}$ and there is no large difference in the concentration factors between the analysis and the Neuber's rule. In the range larger than $50 \mathrm{MPa}$, the strain concentration factor in the finite element analysis increases up to $100 \mathrm{MPa}$ but it turns to decrease with the nominal stress range above $100 \mathrm{MPa}$. The strain concentration factor obtained from the Neuber's rule, on the other hand, increases monotonously with the nominal stress. The stress concentration factor in the finite element analysis agrees with that from the Neuber's rule, with a fair difference giving larger values than the Neuber's rule.

The results indicate that the inelastic strain concentration estimated by the Neuber's rule is accurate for the pure shear deformation but overestimates the strain concentration in the tension deformation.

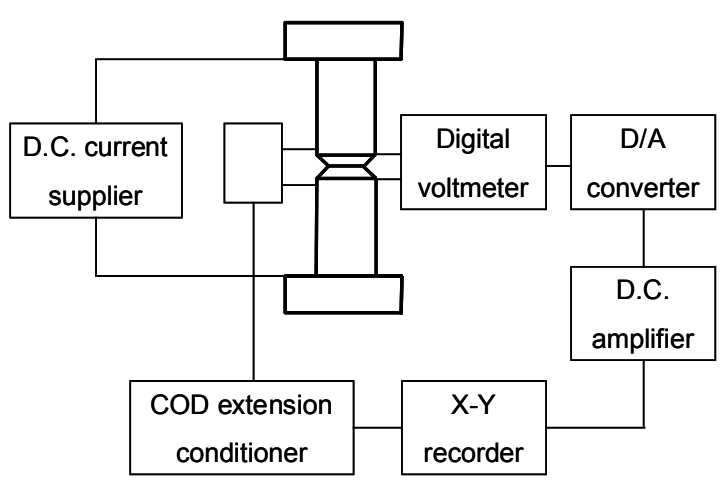

Figure 2. Block diagram for the d.c. potential method.

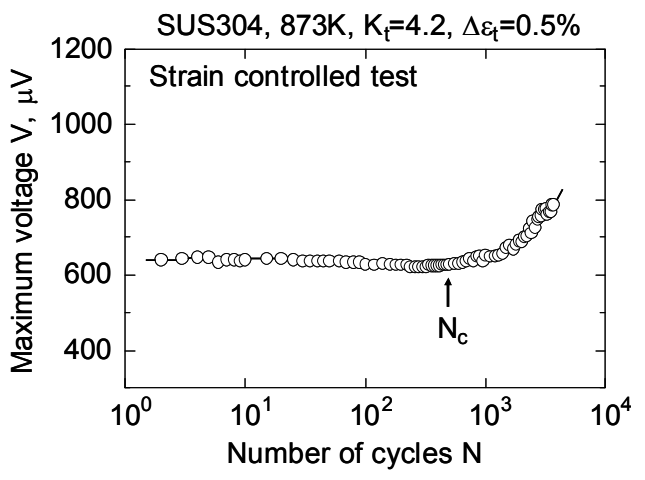

Figure 3. Variation of d.c. potential in the strain controlled test

\section{CRACK INITIATION DETECTION}

An accurate detection of crack initiation is a key technique when discussing the notch effect in low cycle fatigue. Visible observation is applicable for detecting the cycles to crack initiation in plate specimens, but is not applicable in round bar specimens. The authors [7] have developed a d.c. potential method for the accurate detection of the cycles to crack initiation. The schematic of the d.c. potential method is illustrated in Fig.2 [7]. A constant direct current was sent to the specimen and the potential at the notch part was measured. A typical variation of the potential with cycles is shown in Fig.3 [7]. The potential shows almost a constant value until the crack initiation indicated by the arrow in the figure and increased as the crack extension. The crack depth at the crack initiation detected by the method was $0.1 \mathrm{~mm}$ into the specimen that was confirmed experimentally in an direct crack depth measurement. 


\section{NOTCH EFFECT ON UNIAXIAL LOW CYCLE FATIGUE}

Before discussing the notch effect under multiaxial loading, the notch effect in uniaxial push-pull low cycle fatigue is overviewed that is the basis for discussing the notch effect under multiaxial low cycle fatigue. Figure 4 [8] depicts the cycles to crack initiation $\left(\mathrm{N}_{\mathrm{c}}\right)$, for propagation $\left(\mathrm{N}_{\mathrm{p}}\right)$ and to failure $\left(\mathrm{N}_{\mathrm{f}}\right)$ of SUS 304 round bar specimens with the elastic stress concentration factor in nominal strain controlled low cycle fatigue at $873 \mathrm{~K}$. The cycles to failure is defined as the cycles of $25 \%$ nominal stress drop from that at a mid life. The cycles to failure decreased with the stress concentration factor but the cycles to crack initiation more sharply than the cycles to failure. The cycles for crack propagation little decreased with the stress concentration factor.

The figure clearly shows that notches have a significant influence on the cycles to crack initiation and little on those for crack propagation. The crack initiates at the notch root because of highest strain concentration but once the crack initiates, the notch has almost

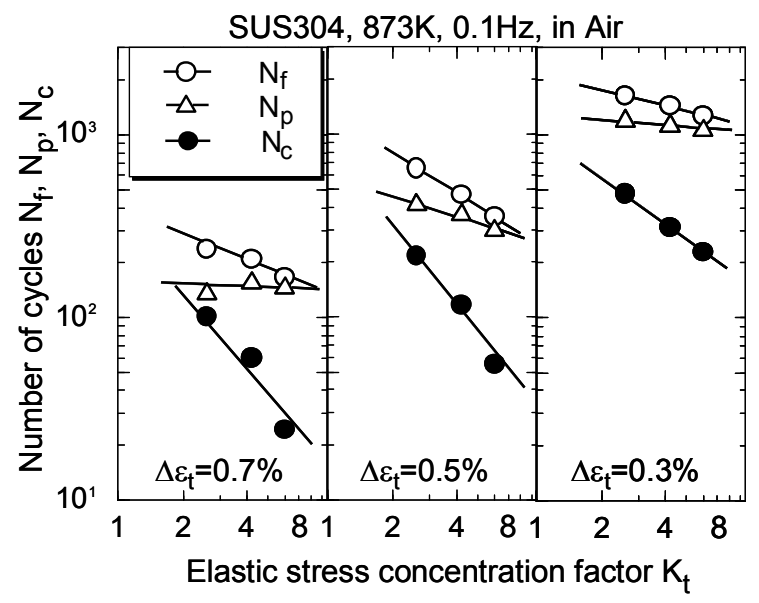

Figure 4. Variations of cycles to crack initiation, for propagation and to failure with elastic stress concentration factor for SUS 304 stainless round bar specimens in nominal strain controlled fatigue at $873 \mathrm{~K}$.

no influence on the crack propagation except the early stage of propagation. The cycles to failure show the combined results of the notch influence on the initiation and on the propagation.

Figure 5 [8] compares the cycles to crack initiation and to failure evaluated by the Neuber's rule with the experimental results. The crack initiation lives of the specimen with the small stress concentration factor are collapsed in a factor of two band while those with the large stress concentration factors were underestimated. All the cycles to failure are underestimated by a factor of 50 at maximum. The cause of this underestimation of the crack initiation lives results from that the Neuber's rule overestimates the strain concentration in tension loading and the failure life includes both the crack initiation life and the crack propagation life that little depends on the stress concentration factor as described above.

The authors [9] proposed a modified equation of the Neuber's rule analytically where the exponent of $\mathrm{K}_{\mathrm{t}}$ is changed from 2 to 1.2 , to take account of the strain constraint in 


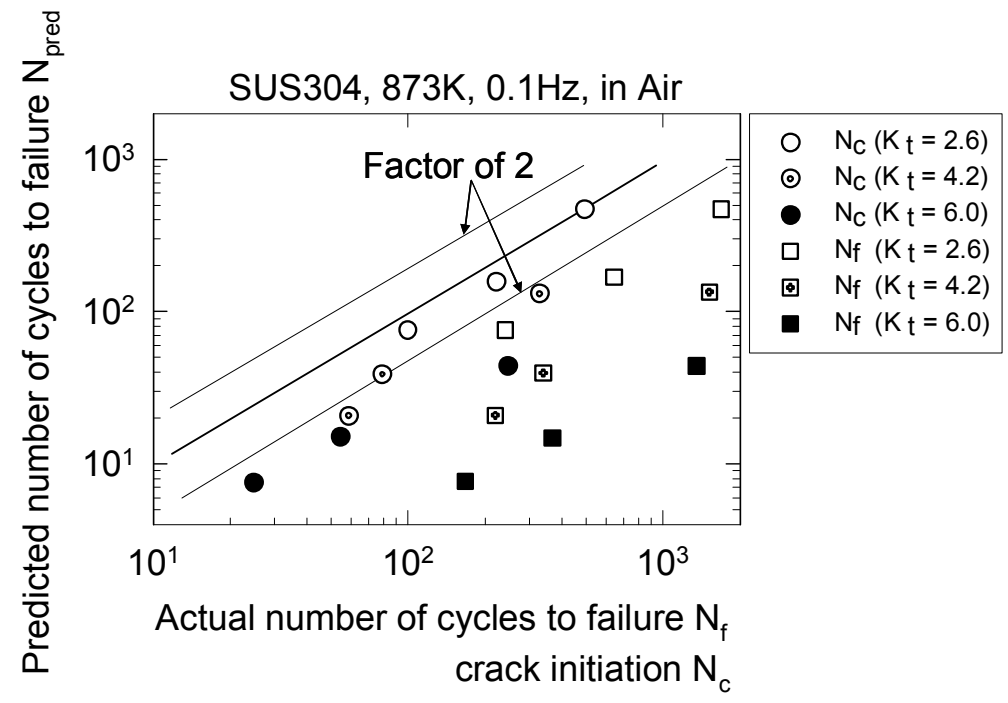

Figure 5. Correlation of predicted lives by the Neuber's rule with inititaion lives and crack failure lives in experiment.

tension loading. The modified Neuber's rule gave the quite improved estimates and all of the failure lives were collapsed within a factor of two band.

\section{NOTCH EFFECT ON PROPORTIONAL MULTIAXIOL LOW CYCLE FATIGUE [10, 11]}

This chapter discusses the notch effect on proportional tension-torsion low cycle fatigue. The elastic stress concentration factors in tension and torsion are defined by the following equation.

$$
K_{t p} \frac{\sigma_{\max }}{\sigma_{n}}, \quad K_{t t}=\frac{\tau_{\max }}{\tau_{n}}
$$

where $K_{t p}$ is the elastic stress concentration factor in tension and $\mathrm{K}_{\mathrm{tt}}$ in torsion loading. $\sigma_{\max }$ and $\tau_{\max }$ are the maximum axial stress and the maximum shear stress at the notch root. $\sigma_{\mathrm{n}}$ and $\tau_{\mathrm{n}}$ are the nominal axial stress and the nominal shear stress. The nominal axial stress is the normal axial stress obtained by dividing the load applied to the notched specimen by the minimum section area at the notch part and the nominal shear stress is the shear stress that occurs at the outer surface of the unnotched specimen with the root section diameter twisted by a torque applied to the notched specimen.

The maximum equivalent stress $\left(\sigma_{\mathrm{eq}}\right)_{\max }$ at the notch root and the nominal equivalent stress $\left(\sigma_{\mathrm{eq}}\right)_{\mathrm{n}}$ are equated as,

$$
\left(\sigma_{\text {eq }}\right)_{\text {max }}=\sqrt{\left(\sigma_{\text {max }}\right)^{2}+3\left(\tau_{\text {max }}\right)^{2}}
$$




$$
\left(\sigma_{\text {eq }}\right)_{n}=\sqrt{\left(\sigma_{n}\right)^{2}+3\left(\tau_{n}\right)^{2}}
$$

The elastic stress concentration factor in combined tension and torsion on Mises base is defined as,

$$
K_{t c}=\frac{\left(\sigma_{\text {eq }}\right)_{\max }}{\left(\sigma_{\text {eq }}\right)_{n}}=\sqrt{\frac{\left(K_{t p}\right)^{2}+3\left(K_{t t} R\right)^{2}}{1+3 R^{2}}}
$$

where $\mathrm{R}$ is the nominal stress ratio defined as $\mathrm{R}=\tau_{\mathrm{n}} / \sigma_{\mathrm{n}}$. The elastic stress concentration factor is different depending on the loading mode at the same specimen geometry. Those in combined tension and torsion are listed in Table 1, where $\lambda$ is the principal stress ratio defined as $\lambda=\sigma_{3} / \sigma_{1} . \quad \sigma_{1}$ and $\sigma_{3}$ are the maximum and minimum principal stresses, respectively.

Figure 6 compares the cycles to failure of SUS 304 notched specimens in tension and torsion low cycle fatigue at $873 \mathrm{~K}$. The tests were performed in nominal stress control. At the same equivalent stress amplitude, the cycles to failure in tension tests are longer

Table 1. Elastic stress concentration factor in combined tension and torsion.

\begin{tabular}{|c|c|c|c|c|}
\hline \multirow{2}{*}{$\begin{array}{c}\text { Notch root radius } \\
\rho, \mathrm{mm}\end{array}$} & \multicolumn{4}{|c|}{ Elastic stress concentration factor } \\
\cline { 2 - 5 } & $\begin{array}{c}\lambda=0 \\
(\mathrm{R}=0)\end{array}$ & $\begin{array}{c}\lambda=-1 / 12 \\
(\mathrm{R}=0.315)\end{array}$ & $\begin{array}{c}\lambda=-1 / 3 \\
(\mathrm{R}=0.866)\end{array}$ & $\begin{array}{c}\lambda=-1 \\
(\mathrm{R}=\infty)\end{array}$ \\
\hline 0.60 & 2.60 & 2.41 & 1.96 & 1.60 \\
\hline 0.20 & 4.20 & 3.84 & 2.98 & 2.24 \\
\hline 0.09 & 6.00 & 5.45 & 4.13 & 2.93 \\
\hline
\end{tabular}

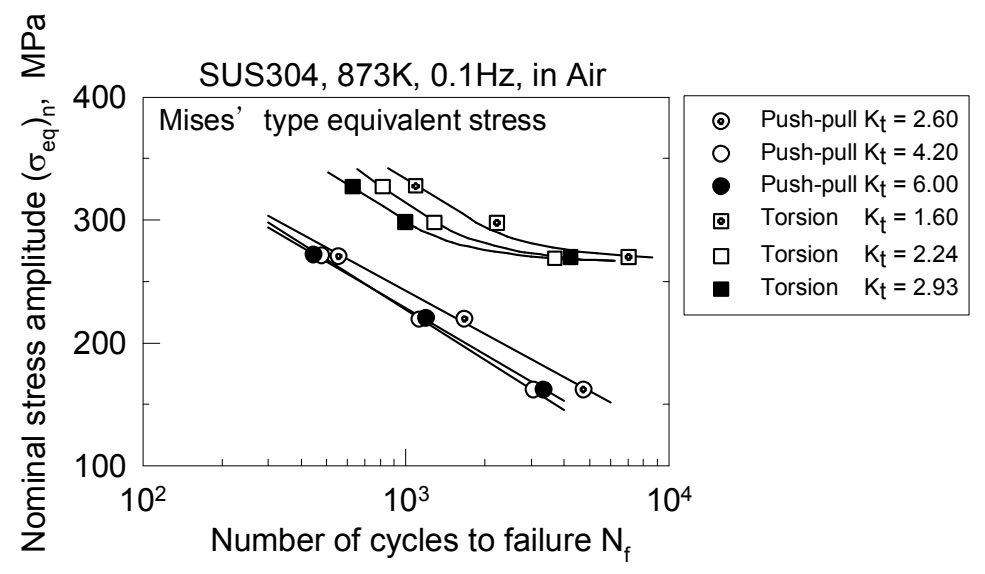

Figure 6. Correlation of the cycles to failure of SUS 304 stainless steel notched specimens in tension and torsion low cycle fatigue at $873 \mathrm{~K}$. 


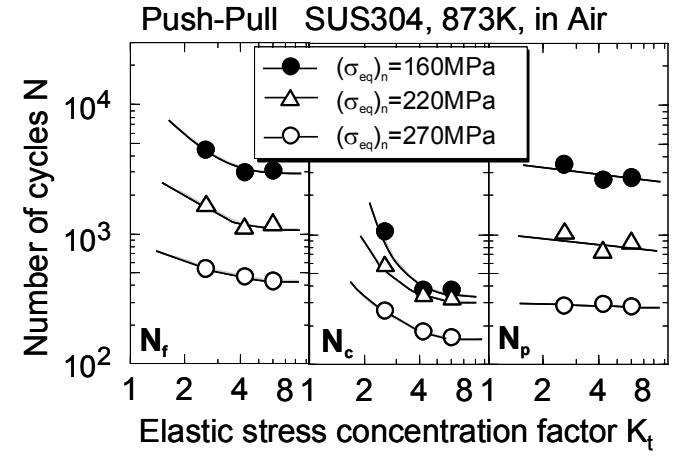

Figure 7. Variations of cycles to failure, to crack and for propagation in tension low cycle fatigue tests.

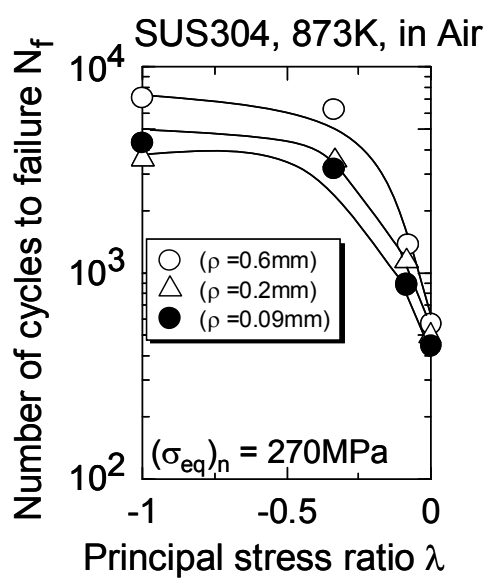

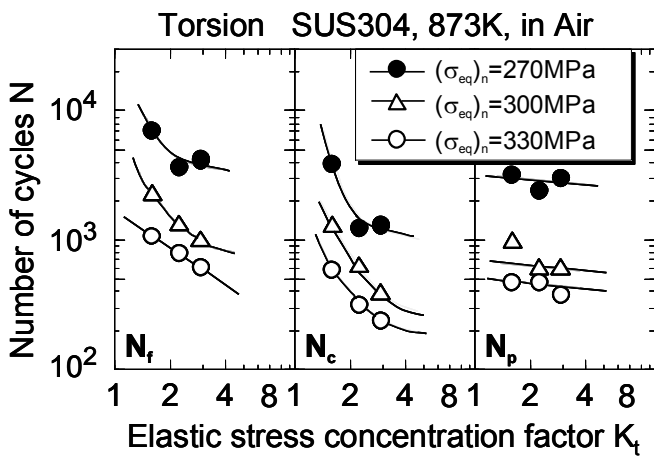

Figure 8. Variations of cycles to failure, to crack and for propagation in torsion low cycle fatigue tests.

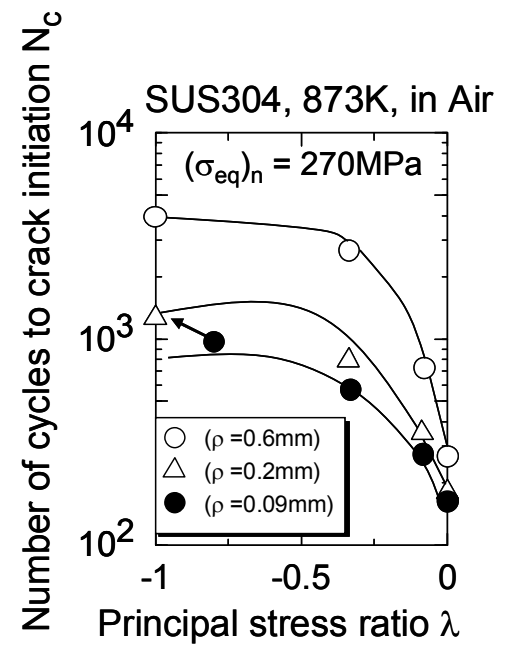

Figure 9. Variations of cycles to failure and to crack initiation in combined torsion and tension.

than those in tension tests. The difference in the low cycle fatigue life results from the differences in the low cycle fatigue between tension and torsion and in the strain concentration between tension and torsion loading.

Figures 7 and 8 show the variations of the cycles to failure, to crack initiation and for propagation in tension and torsion low cycle fatigue for the same specimens as those in Fig.6. The cycles to failure and to crack initiation in tension decreased with the elastic stress concentration and the latter decreased more sharply than the former, Fig.7. The cycles for crack propagation in tension decreased with the elastic stress concentration factor. The same trend was also observed in torsion shown in Fig. 8 but the cycles to failure in torsion appears to decrease more sharply than those in tension. Comparing the results in tension with those in torsion, the reduction in the failure and crack initiation lives in torsion is more significant than that in tension. The cause of the larger reduction in the lives in torsion may result from no constraint of strain in shear 
loading.

The cycles to failure and to crack initiation in tension and torsion are shown in Figs.9 (a) and (b), respectively at the nominal stress amplitude of $270 \mathrm{MPa}$. The cycles to failure and to crack initiation have almost the constant value in the range of $-1 \leq \lambda \leq-1 / 3$ but they rapidly decreased as $\lambda$ in the range more than $\lambda=-1 / 3$. Note that, in the Mises stress controlled test, the principal stress ratio does not have a linear effect on the cycles to failure and to crack initiation, but have a drastic effect in tje larger $\lambda$ range.

When estimating the cycles to failure and to crack initiation of the notched specimen based on the unnotched data, the three points below should be taken into account.

- The method of converting the uniaxial fatigue data of unnotched specimens into the multiaxial data.

- The method of estimating the inelastic strain concentration at the notch root in multiaxial stress states.

- The method of converting the cyclic stress-strain curve in the uniaxial loading into that in multiaxial loading.

Historically, the Mises equivalent strain has been used to correlate the multiaxial low cycle fatigue lives of unnotched specimens but the Mises strain has been demonstrating that the torsion lives were underestimated than the tension lives $[12,13]$. The applicability of other multiaxial low cycle fatigue parameters has been discussed in the literature [13]

The uniaxial low cycle fatigue data of SUS 304 steel at $873 \mathrm{~K}$ used here is

$$
\Delta \varepsilon=1.80 N_{f}^{-0.202}+5.71 N_{f}^{-0.634}
$$

where $\Delta \varepsilon$ is the total strain range and $N_{f}$ the cycles to failure.

The elastic stress concentration factor in tension and torsion is easily obtained in Peterson's chart [14] but those in combined tension and torsion loading should be obtained numerically. This paper uses the elastic stress concentration factor on the Mises base shown in Eq.(5) and also the Mises equivalent stress and strain to express the cyclic stress-strain relationship in multiaxial stress states.

The comparison of the failure and crack initiation lives estimated by the Neuber's rule with the experimental lives is shown in Fig.10 (a) in tension and (b) in torsion. In the tension shown in Fig.10 (a), the cycles to failure and to crack initiation of the smaller $\mathrm{K}_{\mathrm{t}}$ specimens are located in a factor 2 band but those of the larger $K_{t}$ specimens are underestimated by more than a factor two. The degree of the underestimation becomes more significant as $\mathrm{K}_{\mathrm{t}}$ increases. In the torsion in Fig.10 (b), almost all the cycles to failure and to crack initiation are collapsed in a factor of two band.

The Neuber's rule was derived in prismatic shear so that it did not give an appropriate estimate in the tension test where the actual strain concentration was smaller than the estimate, and it gave a proper estimate in the torsion test where the actual deformation mode is the same as the Neuber's rule. 


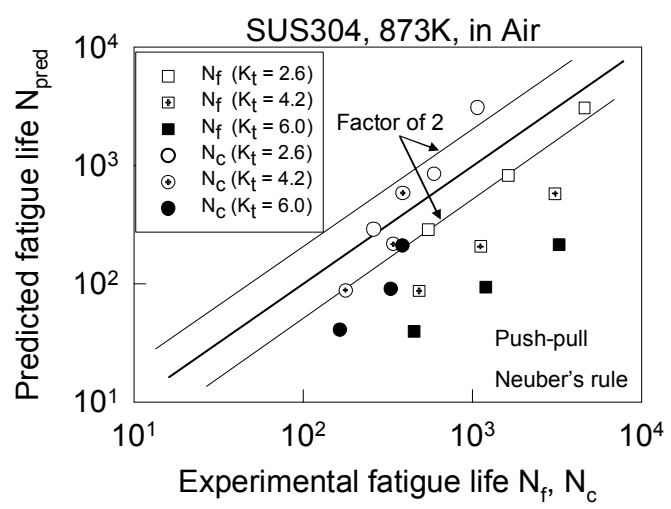

(a) Tension

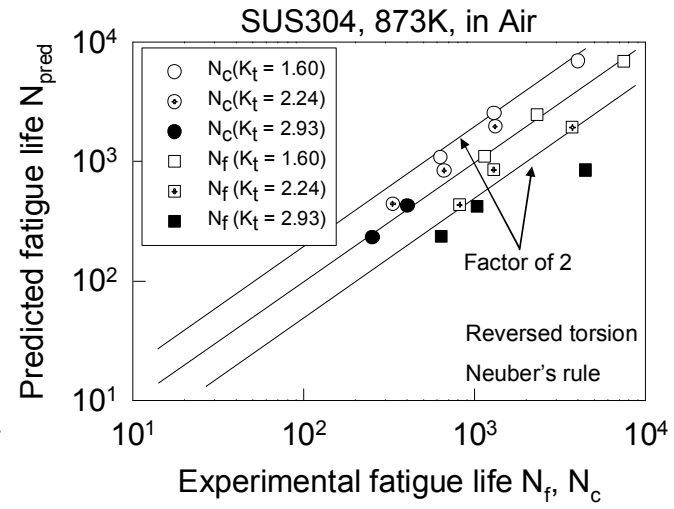

(b) Torsion

Figure 10. Comparison of fatigue lives predicted by the Neuber's rule with experimental lives (a) in the push-pull test and (b) in the torsion test.

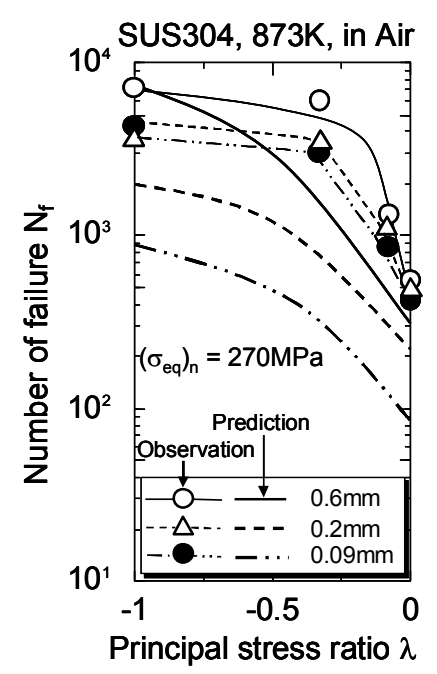

(a)

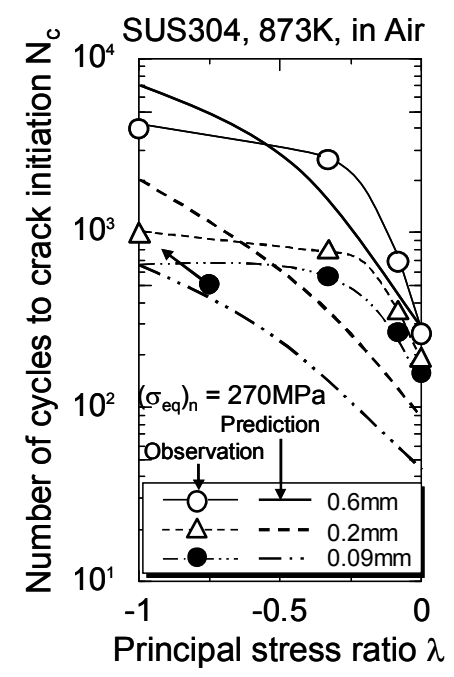

(b)

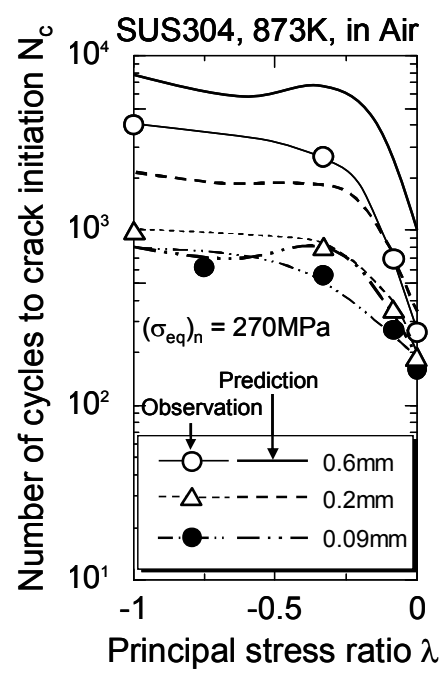

(c)

Figure 11. Comparison of the cycles to failure and to crack predicted by the Neuber's and modified Neuber's rules with the experimental lives.

The variations of the cycles to failure and to crack initiation with the principal stress ratio are shown in Fig.11. Figure 11 (a) compares the cycles to failure and Fig.11 (b) the cycles to crack initiation. In both the figures, the estimated lives agree with the experimental lives in torsion whereas the cycles to failure in experiments are longer than those to crack. However, the Neuber's rule underestimates the cycles to failure and to crack in tension as already discussed in Fig.10. The fatigue lives estimated decrease as $\lambda$ decreases as well as the experimental fatigue lives but the decreasing rate of the estimated lives is different from that of the experimental lives. The estimated 
lives decrease monotonously as $\lambda$ increases but the experimental lives do not monotonously.

As discussed previously, the modified Neuber's rule, in which the value of the exponent of $\mathrm{K}_{\mathrm{t}}$ is changed from 2 to 1.2 to take account of the strain constraint in tension, improves the accuracy of life estimation. Figure 11 (c) comparers the lives estimated by the modified Neuber's rule with the experimental lives for the cycles to crack initiation. The estimated results closely agree with the experimental lives, so that the modified Neuber's rule is applicable to the crack initiation estimate in tension and torsion multiaxial stress state.

The authors proposed the notch root displacement strain expressed by the following equation to estimate the crack initiation lives of the notched specimens in tension and torsion.

$$
\bar{\varepsilon}=K_{t c}\left(\varepsilon_{\text {eq }}\right)_{n}
$$

$\mathrm{K}_{\mathrm{tc}}$ is the elastic stress concentration factor in combined tension and torsion expressed in Eq.(5) and $\left(\varepsilon_{\mathrm{eq}}\right)_{\mathrm{n}}$ is the nominal Mises equivalent strain in Eq.(4). The strain physically expresses the notch opening displacement of the notched specimen and was derived by the finite element analysis. The comparison of the crack initiation lives estimated by Eq.(7) with the experimental lives is shown in Fig.12. Approximately 75 percent of the data are collapsed in a factor of 2 band. Note that some of the axial tension data are located outside the factor of 2 band. These data may result from the error of the a.c. potential method or stress dependency of crack initiation life.

The successful correlation of the crack initiation life with the notch root opening displacement means physically that the local displacement at the notch root is an appropriate crack initiation criterion to assess the crack initiation life in the different deformation modes.

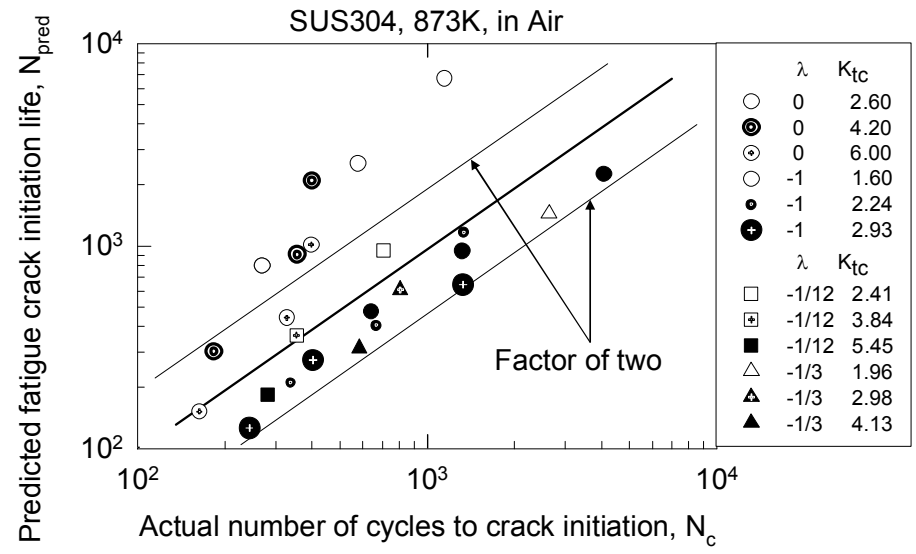

Figure 12. Comparison of the crack initiation lives estimated Eq.(7) with the experimental crack initiation lives. 


\section{NOTCH EFFECT ON NONPROPORTOONAL MULTIAXIAL LOW CYCLE FATIGUE}

\section{Nonproportional low cycle fatigue lives of unnotched specimen}

Figure 14 [15] correlates the nonproportional low cycle fatigue lives of the unnotched hollow cylinder specimens (O.D. $11 \mathrm{~mm}$, I.D. $9 \mathrm{~mm}$ ) under the fifteen strain paths shown in Fig.13 with the maximum principal strain range. The figure clearly shows that the nonproportional fatigue lives are mostly shorter than the proportional fatigue lives depending on the strain path. The smallest fatigue lives are found in Case10, 12 and 13 which are about 20 times smaller than the proportional fatigue lives. To correlate the nonproportional low cycle fatigue lives, Itoh et al.,[15] proposed the nonproportional strain expressed by the following equation.

$$
\Delta \varepsilon_{N P}=\left(1+\alpha f_{N P}\right) \Delta \varepsilon_{I}
$$

In the equation, $f_{N P}$ is the nonproportional factor shown Eq.(9) that expresses the severity of nonproportional loading, and $\alpha$ is the material constant expressing the material dependency on nonproportional fatigue life.

$$
f_{N P}=\frac{1.57}{T \varepsilon_{\text {I } \max }} \int_{0}^{T}(|\sin \xi(t)|) \varepsilon_{I}(t) d t
$$

The correlation of nonproportional low cycle fatigue lives with the nonproportional strain is shown in Fig.15 [15]. Almost all the low cycle fatigue lives including those in nonproportional loading are well correlated within a small scatter band. Note that the main cause of the reduction of low cycle fatigue lives is attributed to the additional
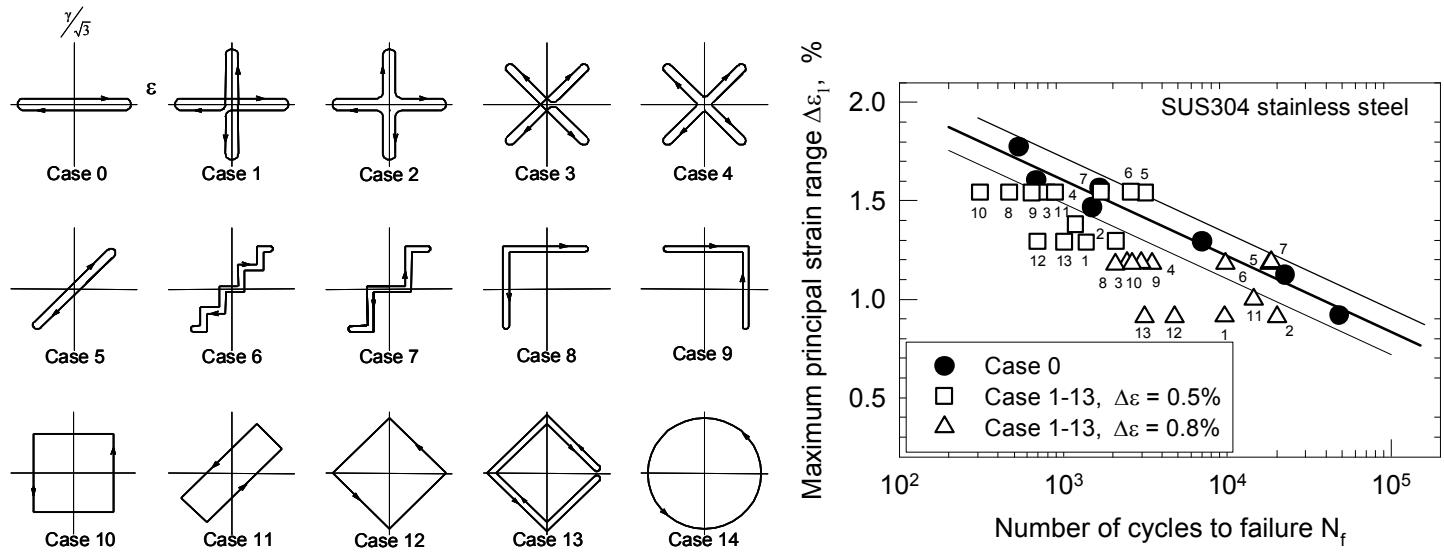

Figure 13. Fifteen strain paths.

Fig.14 Correlation of the nonproportional low cycle fatigue lives under fifteen strain path with the maximum principal strain range. 


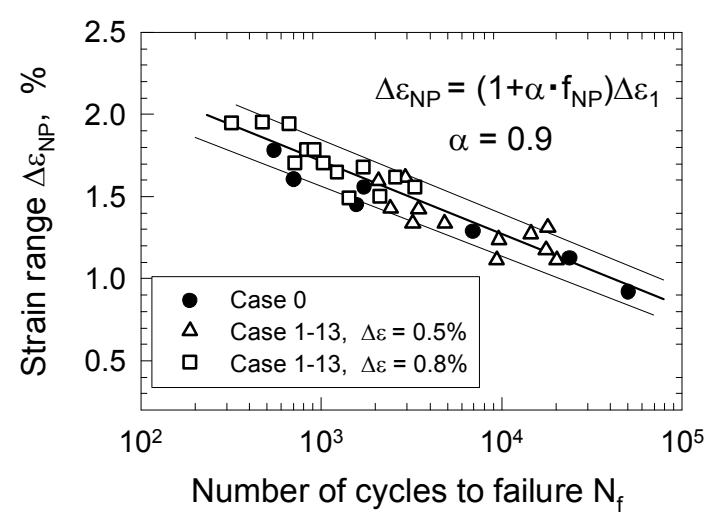

Figure 15. Correlation of nonproportional low cycle fatigue lives of unnotched specimens with the nonproportional strain.

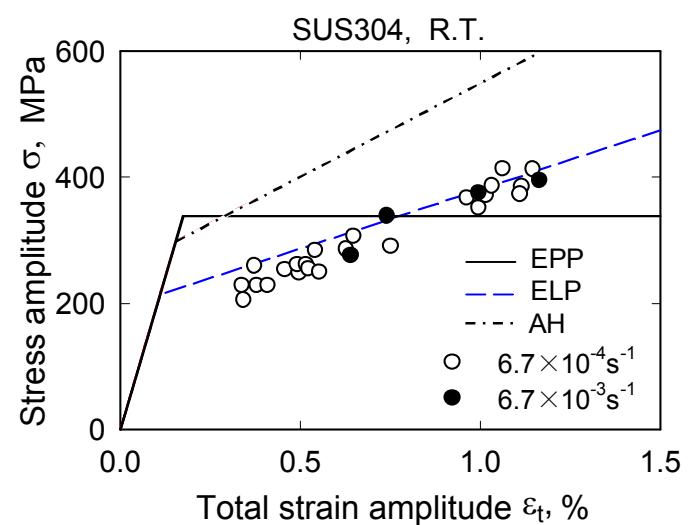

Figure 16. Three constitutive models used in finite element analysis.

hardening due to the nonproportional loading but recent studies demonstrated the reduction also occurred in materials that showed no additional hardening. The main cause of these materials is not clearly demonstrated but the cracking mechanism is presumably attributed to the reduction in such materials.

\section{Nonproportional low cycle fatigue lives}

To evaluate the cycles to crack initiation of notched specimens fatigued in nonproportional loading, he local strains at the notch root be estimated. There are couples of researches performed to obtain the local strains under nonproportional loading [16,17], and this paper uses the finite element method to calculate the local strains for SUS 304 stainless steel and the Neuber's rule to Mod.9Cr-1Mo steel.

Finite element analyses were performed to estimate the local strain at the notch root using the three constitutive relationships, Fig.16 [18]. The three constitutive relationships are (a) the elastic-perfectly plastic model (EPP), (b) the elastic-linear plastic model (ELP) and (c) elastic-linear plastic model taking account of additional hardening (AH). The EPP model only needs the Young's modulus and the yield stress, and is used from the simplicity than the accuracy. The LEP is the model used most frequently but it does not taking account of the additional hardening due to nonproportional loading. The AH hardening model is the model taking account of the additional hardening and the yield stress and the hardening coefficient are raised from those in the LEP model.

Figure 17 [18] correlates the cycles to crack initiation of the notched specimens fatigued in the fifteen strain paths with the nonproportional strain range, where the dashed line is the cycles to failure of the unnotched specimens. The nonproportional strain range calculated using the EEP model underestimates the crack initiation life at the large strain ranges but appropriately at low strain range, Fig.17 (a). The degree of the underestimation becomes smaller at the larger strain ranges in the ELP model and almost the same trend is found in the ELP model at the low strain ranges as that in EEP 

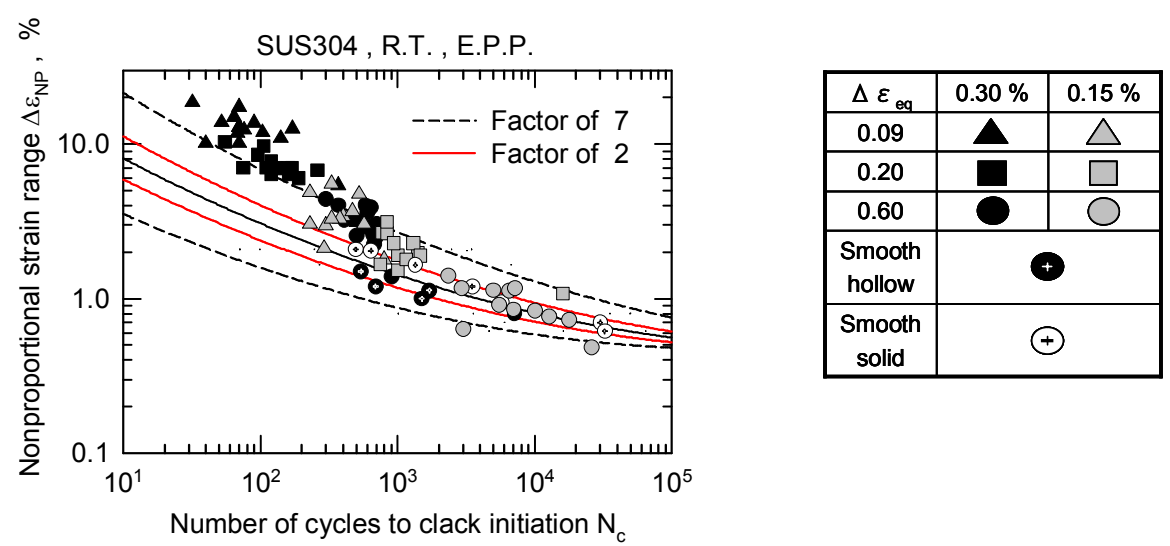

(a)EPP model

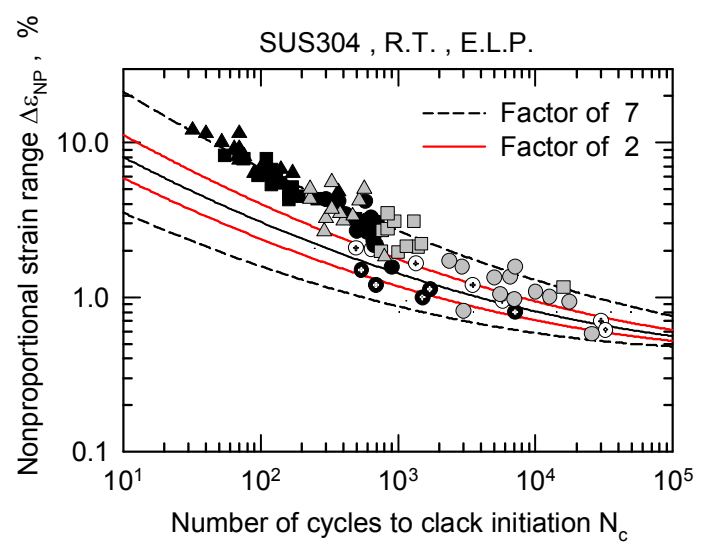

(b)ELP model

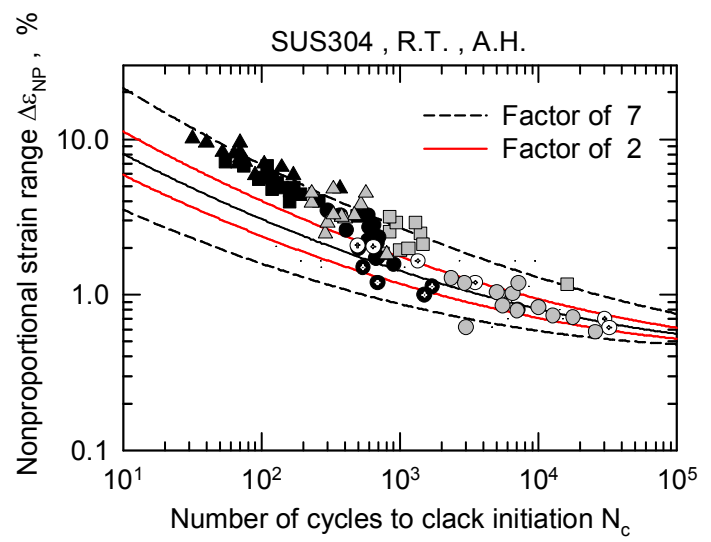

(c) AH model

Figure 17. Correlation of the cycles to crack initiation of notched specimens with the nonproportional strain range.

model, Fig.17 (b). The underestimate of the crack initiation life at high strain ranges in the two models results from the additional hardening due to nonproportional loading at the notch root. The notch root underwent the significant nonproportional straining and hardened more than the other parts. The strain range at the notch root reduced by the additional hardening and the smaller strain range extended the fatigue lives than estimated. A slight improvement of the correlation was found in Fig17 (c) using the AH model. The underestimation is still large in the correlation at the large strain ranges. The cause of the underestimation should be analyzed more in future.

The similar nonproportional low cycle fatigue tests were performed using Mod.9Cr-1Mo steel that is a little additional hardening material. The local strain at the notch root was calculated by the Neuber's rule. The strain paths employed are Case 0 , 1, 3, 5 and 10. The local strain trajectory calculated by the Neuber's rule is shown in Fig.18 [17]. In the figure, (a), (b) and (c) are controlled strain path, the axial load-displacement relationship and the torque-twist angle per unit length, respectively. 


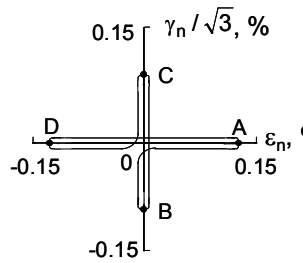

(a)

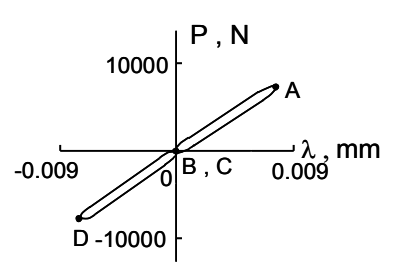

(b)

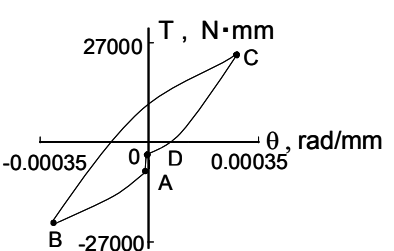

(c)

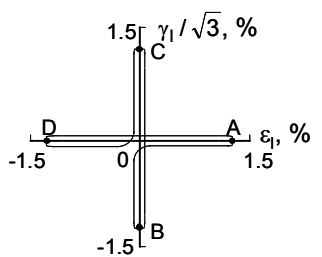

(d)

(a) Controlled strain path

(b) Axial load - axial displacement relationship

(c) Torque - twist angle per unit length relationship

(d) Local strain path at notch root

Figure 18. Four hysteresis loops for $\rho=0.09 \mathrm{~mm}$ in Case 1.

Fig.18 (d) is the local axial and shear strains calculated by the Neuber's rule, following the method presented previously. The local strains at A (axial strain) and $\mathrm{C}$ (shear strain) and those at $\mathrm{D}$ and $\mathrm{B}$ were evaluated by setting the minus sign to the strains at $\mathrm{A}$ and $\mathrm{C}$ considering the symmetry of strain waveform.

Figures 20 and 21 [17] correlate the cycles to crack initiation and to failure with the maximum principal strain range and ASME strain range [6]. The ASME strain range is the strain range recommended in the ASME PVP code and is expressed as,

$$
\Delta \varepsilon_{A S M E}=M A X\left[\left\{\left(\varepsilon_{A}-\varepsilon_{B}\right)^{2}+\frac{\left(\gamma_{A}-\gamma_{B}\right)^{2}}{3}\right\}^{\frac{1}{2}}\right]
$$

$\mathrm{A}$ and $\mathrm{B}$ are the times to maximize the value in the bracket. The maximum principal strain range overestimates most of the cycles to crack by a factor of 11 at maximum, Fig,19 (a), and also overestimates the cycles to failure by a factor of 5, Fig.19 (b). The ASME strain range gives almost the same trend as the maximum principal strain range but the degree of the overestimate is smaller. The ASME strain range overestimates the cycles to crack by a factor of 5 at maximum, Figs.20 (a) and (b). The results of the correlation of the cycles to crack initiation of the two materials suggest that the correlation of the crack initiation lives of the notched specimens is material dependent. The estimate of the cycles to crack initiation of the material that shows the additional hardening under nonproportional loading has a trend to be conservative and that of the material that shows a little additional hardening a trend to be unconservative. This paper applied the different methods of estimating the cycles to crack initiation between SUS 304 and Mod.9Cr-1Mo ; the finite element method to the SUS 304 and the Neuber's rule to Mod.9Cr-1Mo, so the comparison using the same method should be applied in a future research. 


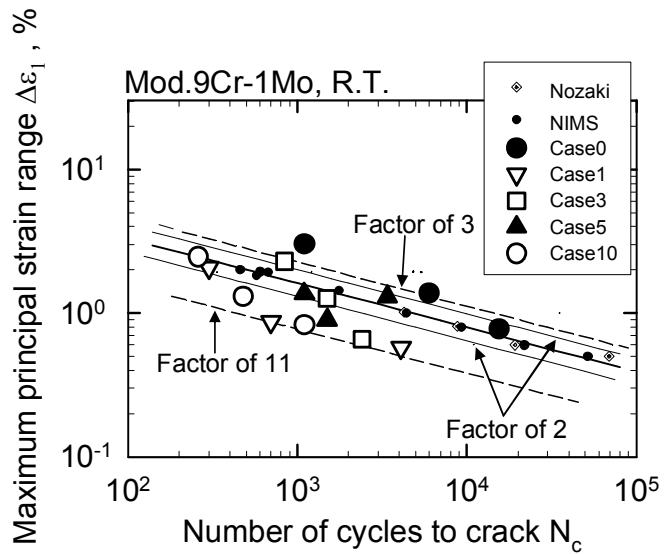

(a) $\mathrm{N}_{\mathrm{c}}$

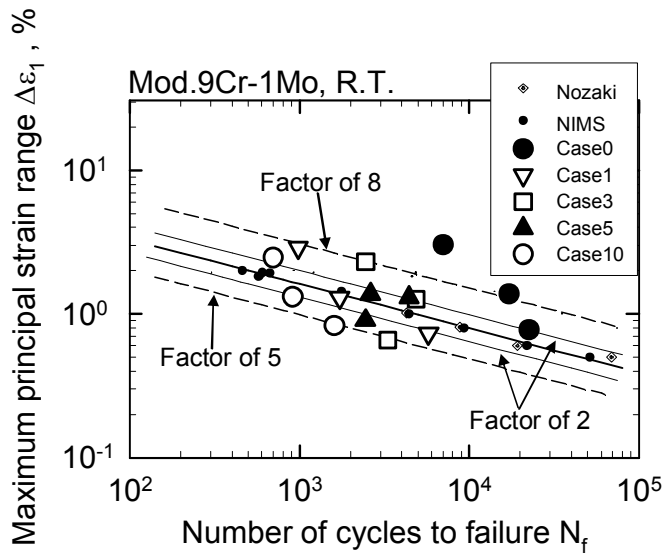

(b) $\mathrm{N}_{\mathrm{f}}$

Figure 19. Correlation of cycles to crack with maximum principal strain range.

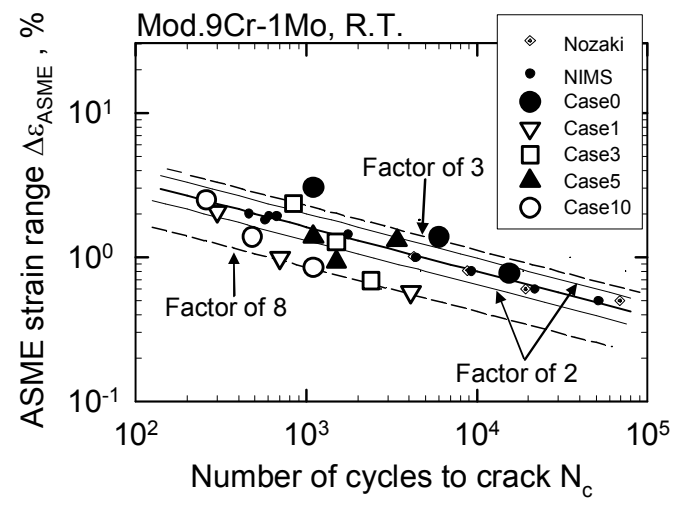

(a) $\mathrm{N}_{\mathrm{c}}$

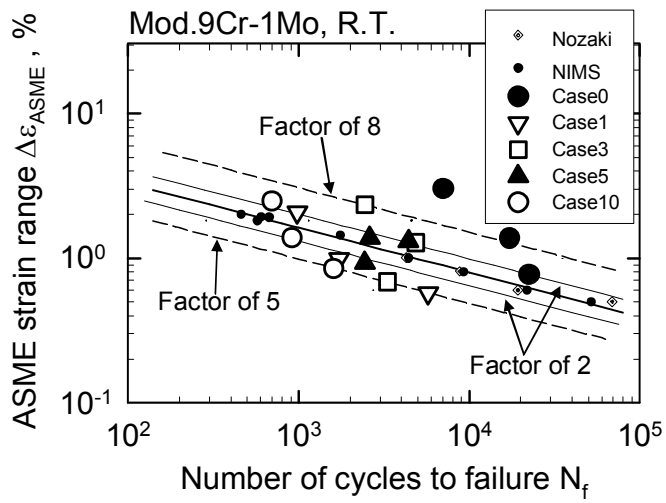

(b) $\mathrm{N}_{\mathrm{f}}$

Figure 20. Correlation of cycles to crack initiation and to failure with ASME strain range.

\section{CONCLUSIONS}

(1) The cycles to crack initiation were significantly influenced by notch while the cycle for crack propagation little influenced by notch. The cycles to failure was the combined effects of the cycles to crack initiation and for propagation.

(2) The Neuber's rule underestimated the cycles to crack initiation in tension but properly estimated those in torsion. The Neuber's rule theoretically derived for pure shear so that the experimental results were consistent with the theoretical background. The modified Neuber's rule was discussed to improve the estimate of the cycles to crack initiation in tension.

(3) The nonproportional strain calculated by finite element analysis underestimated the cycles to crack of SUS 304 stainless steel at large strain ranges but properly estimated at the low strain ranges. These results were discussed in relation with the additional hardening at the notch root using the three constitutive models. 
(4) The maximum principal and ASME strain ranges overestimated the cycles to crack initiation for Mod.9Cr-1Mo steel. The results suggest that the estimation of the cycles to crack initiation under nonproportional loading was material dependent. The material that showed the additional hardening under nonproportional loading gave a conservative estimate but the material that showed little additional hardening an unconservative estimate.

\section{REFERENCES}

[1] Dowling, E., (1998), Mechanical Behavior of Materials, Prentice Hall, 420-487.

[2] Socie, D., Marquis, G. (2000), Multiaxial Fatigue, SAE International, 341-409.

[3] Susmel, L., (2009), Multiaxial Notch Fatigue, Woodhead Publishing Ltd.

[4] Neuber, H., (1958), Kerbspannungslehre, Springer-Verlag.

[5] Neuber, H., (1961), ASME, J. Applied Mech. 28(4), 544-550.

[6] ASME Boiler and Pressure Vessel Code, Section III, Division 1, Subsection $\mathrm{NH}(2007)$.

[7] Sakane, M., Ohnami, M., (1988), ASME, J. Eng. Mater. Tech. 110(3), 247-252.

[8] Sakane, M., Ohnami, M., (1986), ASME, J. Eng. Mater. Tech. 108(4), 279-284.

[9] Sakane, M., Ohnami, M., (1983), ASME, J. Eng. Mater. Tech. 105(2), 75-80.

[10] Umeda, H., Sakane, M., Ohnami, M., (1989), ASME, J. Eng. Mater. Tech. 111(3), 286-293.

[11] Umeda, H., Sakane, M., Ohnami, M., (1990), ASME, J. Eng. Mater. Tech. 112(3), 429-434.

[12] Sakane, M., Ohnami, M., Sawada, M., (1987), ASME, J. Eng. Mater. Tech. 109(3),

236-243.

[13] Itoh, T., Sakane, M., Ohnami, M., (1994), ASME, J. Eng. Mater. Tech. 116(1), 90-98.

[14] Peterson, R., (1953), Stress Concentration Design Factors, John Wiley and Sons.

[15] Itoh, T., Sakane, M., Ohnami, M., Socie, D., (1995), ASME, J. Eng. Mater. Tech. 117(3), 285-292.

[16] Barkey, M., Socie, D., Hsia, K., (1994), ASME, J. Eng. Mater. Tech. 116(2), 173-180.

[17] Kim, T., Zhang, S., Sakane, M., (2010), Trans. JSME (A), submitted.

[18] Suzaki, T., Sakane, M., (2003), Proc. $78^{\text {th }}$ JSME Kansai Annual Meeting, 1-11-1-12 - 1-11-1-13. 